\title{
Factors Influencing Development of Depressive Illness among Parkinson's Disease Patients
}

\author{
Provat Kumar Sarkar ${ }^{1}$, Hasan Zahidur Rahman², Mahua Chandra ${ }^{3}$, Anis Ahmed ${ }^{4}$, Md. Enayet- Ul-Islam ${ }^{5}$,
} Abdul Kader Shaikh ${ }^{6}$, Rashed Imam Zahid ${ }^{7}$, Gurudas Mondal ${ }^{8}$, Abu Nayeem', Afzal Momin ${ }^{10}$

${ }^{1}$ Assistant Professor, Department of Neurology, National Institute of Neurosciences and Hospital, Dhaka, Bangladesh; ${ }^{2}$ Professor, Department of Neurology, Bangabandhu Sheikh Mujib Medical University, Dhaka, Bangladesh; ${ }^{3}$ Junior consultant, Department of Paediatric Neurology,

National Institute of Neurosciences and Hospital, Dhaka, Bangladesh; ${ }^{4}$ Assistant Professor, Department of Neurology, Bangabandhu Sheikh Mujib Medical University, Dhaka, Bangladesh; ${ }^{5}$ Registrar, Department of Neurology, National Institute of Neurosciences and Hospital, Dhaka, Bangladesh; ${ }^{6}$ Associate Professor, Department of Neurology, Bangabandhu Sheikh Mujib Medical University, Dhaka, Bangladesh; ${ }^{7}$ Registrar, Department of Neurology, National Institute of Neurosciences and hospital, Dhaka, Bangladesh; ${ }^{8}$ Assistant Professor, Department of Neurology, National Institute of Neurosciences and Hospital, Dhaka, Bangladesh; ${ }^{9}$ Associate Professor, Department of Clinical Neurology, National Institute of Neurosciences and Hospital, Dhaka, Bangladesh; ${ }^{10}$ Associate Professor, Department of Clinical Neurology, National Institute of Neurosciences and Hospital, Dhaka, Bangladesh

[Received: 12 April 2019; Accepted: 20 May 2019; Published: 1 July 2019]

\begin{abstract}
Background: Depressive illness is present among Parkinson's disease (PD) patients. Objective: The purpose of the present study was to see the influencing factors of development of depressive illness among Parkinson's disease patients. Methodology: This comparative cross-sectional study was carried out in the Department of Neurology and Department of Psychiatry at Bangabandhu Sheikh Mujib Medical University (BSMMU), Dhaka, Bangladesh from July 2009 to June 2011 for a period of two (2) years. Parkinson's disease patients who were attended at the movement disorder clinic and general OPD of Department of Neurology and in-patient department of Neurology at BSMMU, Dhaka were selected as study population. Patients with Parkinson's plus syndrome, with dementia or other causes of parkinsonism like vascular or drug induced parkinsonism were excluded from this study. Data were collected by filling structured clinical questionnaire, then filling up of 'structured clinical interview for DSM-IV Axis I disorders' (SCID-CV) and self-reported 'Depression scale' questionnaire. Parkinson disease was diagnosed by neurologist by the presence of two or more of the four cardinal criteria namely tremor, rigidity, bradykinesia and postural instability. Then patients were screened for depression by a psychiatrist of Department of Psychiatry at BSMMU, Dhaka. Result: A total of 100 Parkinson's disease patients were interviewed and 80 patients ultimately participated in the study. The mean age of total Parkinson's disease patients was $57.71 \pm 12.36$ years ranging from 35 to 82 years with highest percentage (35\%) had age group 65 years or above, $28.7 \%$ in 55 to 64 years, $22.5 \%$ in 45 to 54 years and lowest percentage $(13.8 \%)$ in age group less than 45 years. Among 80 Parkinson's disease patients, depression was present in $34(42 \%)$ patients and was absent in 46 $(58 \%)$ patients. Diabetes mellitus $(\mathrm{p}=0.125)$, hypertension $(\mathrm{p}=0.097)$, hypothyroidism $(\mathrm{p}=1.000)$, other illness $(\mathrm{p}=0.595)$, family history of PD $(\mathrm{p}=0.758)$ and levodopa use $(\mathrm{p}=0.661)$ were not significantly associated with the development of depressive illness in Parkinson's disease. Conclusion: Diabetes mellitus (DM), hypertension (HTN), hypothyroidism, other illness, family history of PD and levodopa use do not significantly influence in the development of depressive illness among the Parkinson's disease. [Journal of National Institute of Neurosciences Bangladesh, 2019;5(2):106-110]
\end{abstract}

Keywords: Risk factors; development; depressive illness; Parkinson's Disease

Correspondence: Dr. Provat Kumar Sarkar, Assistant Professor, Department of Neurology, National Institute of Neurosciences and Hospital, Sher-E-Bangla Nagar, Dhaka-1207, Bangladesh; Cell No.: +8801711465164; Email: provatdr107@gmail.com

Conflict of interest: There is no conflict of interest relevant to this paper to disclose.

Funding agency: This research project was not funded by any group or any institution.

Contribution to authors: PK Sarkar is the main researcher of the study. He prepared the protocol, collected data and wrote whole part of manuscript. HZ Rahman was guide of the study. M Chandra, A Ahmed, ME Islam, RI zahid, GD Mondal helped in data collection and preparing manuscript. Nayeem A, AK Shaikh \& A Momin helped in writing manuscript

How to cite this article: Sarkar PK, Rahman HZ, Chandra M, Ahmed A, Islam MEU, Shaikh AK, Zahid RI, Mondal G, Nayeem A \& Momin A. Factors Influencing Development of Depressive Illness among Parkinson's Disease Patients. J Natl Inst Neurosci Bangladesh, 2019;5(2): 106-110

Copyright: (C2019. Sarkar et al. Published by Journal of National Institute of Neurosciences Bangladesh. This article is published under the Creative Commons CC BY-NC License (https://creativecommons.org/licenses/by-nc/4.0/). This license permits use, distribution and reproduction in any medium, provided the original work is properly cited, and is not used for commercial purposes. 


\section{Introduction}

Parkinson's disease is observed in all countries and in all socio-economic classes. In Asians the incidence is one third to one-half than in whites ${ }^{1}$. The disease is frequent in North America, where there are approximately one million patients, constituting about $1 \%$ of the population over the age of 60 years in the USA2. In European countries it is more than $1.0 \%$ individual older than 55 years of age and more than $3.0 \%$ of those older than 75 years of age ${ }^{3}$. There is no community data in Bangladesh regarding its prevalence.

Depression is a serious medical condition that affects thoughts, feelings, and the ability to function in everyday life. The central features of depressive disorders are depressed mood, pessimistic thinking, and lack of enjoyment, reduced energy and slowness. Of these, depressed mood is usually, but not invariably the most prominent symptom ${ }^{4}$. Depression can occur at any age. The lifetime risk of major depressive disorder in community samples varied from $10.0 \%$ to $25.0 \%$ for women and from $5.0 \%$ to $12.0 \%$ for men ${ }^{5}$. In Bangladesh prevalence of major depression in general population is $4.6 \%$ cases $^{6}$.

The etiology of depression in PD is complex and may be due to a combination of endogenous (neurochemically based) and exogenous (environmental) factors. Exogenous factors are a reaction to being diagnosed with a disabling, chronic illness for which there is no known cure ${ }^{7}$. It may be endogenous and caused by neurological changes associated with the disease process itself. The favoured hypothesis for the etiology of depression in PD is that it occurs as a primary consequence of brain dysfunction ${ }^{8}$. Changes in three major neurochemical systems are involved in the etiology of PD, namely, dopamine, noradrenaline and serotonin (5HT). These neurotransmitter pathways are intimately associated. Depression has been linked in particular to serotonergic neurotransmitter pathways?. Degeneration of dopaminergic neurons of the mesocorticolimbic pathway may cause dysfunction of the orbitofrontal cortex, which secondarily affects serotonergic connections of the dorsal raphae nucleus. Disruption of serotonergic pathways may be an important factor in the increased prevalence of depression in PD patients ${ }^{10}$.

Some risk factors for development of Parkinson's disease are positive family history, male gender, head injury, exposures to pesticides, consumption of well water and rural living. Factors linked to a reduced incidence of Parkinson's disease are coffee drinking, smoking, use of NSAIDs and estrogen replacement in post-menopausal women ${ }^{11}$. This present study was undertaken to see the influencing factors of development of depressive illness among Parkinson's disease patients.

\section{Methodology}

This was a comparative cross-sectional study. This study was carried out in the Department of Neurology and Department of Psychiatry at Bangabandhu Sheikh Mujib Medical University (BSMMU), Dhaka, Bangladesh from July 2009 to June 2011 for a period of two (2) years. Parkinson's disease patients who were attended at the movement disorder clinic and general OPD of Department of Neurology and in-patient department of Neurology at BSMMU, Dhaka were selected as study population. Prior to commencement of this study, this research protocol was approved by the Local Ethical Committee of BSMMU, Dhaka. Patients with Parkinson plus syndrome, with dementia or other causes of parkinsonism like vascular or drug induced parkinsonism were excluded from this study. Data were collected by face to face interview by filling structured clinical questionnaire, then filling up of 'structured clinical interview for DSM-IV Axis I disorders' (SCID-CV) and self-reported 'Depression scale' questionnaire $^{12}$. Parkinson's disease was diagnosed by neurologist by the presence of two or more of the four cardinal criteria namely tremor, rigidity, bradykinesia and postural instability. Then patients were screened for depression by a psychiatrist of Department of Psychiatry at BSMMU, Dhaka who used SCID-CV. Patients were considered to have depression if they had 5 or more of the 9 symptoms of the major depressive episode criteria and mood disorder due to a general medical condition criteria of the DSM-IV-TR using the SCID-CV. Mini Mental State Examination (MMSE, Bangla version) was done to exclude dementia in PD patients. To exclude vascular lesions and other degenerative disorders, a good number of patients underwent radiological investigations (MRI or CT scan of brain). Thyroid function tests (Free T4 and TSH) and blood glucose were done to detect associated hypothyroidism and diabetes mellitus respectively. Patients were requested to report with the investigation reports. All data were recorded systematically in preformed data collection form. Quantitative data were expressed as mean and standard deviation and qualitative data as frequency distribution and percentage. Statistical analysis was performed by using SPSS for windows version 20.0. Association was analyzed by logistic regression analysis. 95\% confidence limit was taken. ' $\mathrm{P}$ ' value was taken as $<0.05$ as level of significance. 


\section{Results}

A total of 100 Parkinson's disease patients were interviewed and 80 patients ultimately participated in the study. Patients were interviewed for presence of depression and divided into two groups considering presence of depression and different variables were compared between two groups.

Table 1: Age and sex distribution of the study patients $(\mathrm{n}=80)$

\begin{tabular}{lcccc}
\hline Age Group & Male & Female & Total & P value \\
\hline$<45$ Years & $7(11.5 \%)$ & $04(21.1 \%)$ & $11(13.8 \%)$ & $0.281^{*}$ \\
45 to 54 Years & $13(21.3 \%)$ & $05(26.3 \%)$ & $18(22.5 \%)$ & $0.754^{*}$ \\
55 to 64 Years & $18(29.5 \%)$ & $05(26.3 \%)$ & $23(28.7 \%)$ & $0.788^{*}$ \\
$\geq 65$ & $23(37.7 \%)$ & $05(26.3 \%)$ & $28(35.0 \%)$ & $0.363^{*}$ \\
Total & $\mathbf{6 1}(\mathbf{1 0 0 . 0} \%)$ & $\mathbf{1 9}(\mathbf{1 0 0 . 0} \%)$ & $\mathbf{8 0}(\mathbf{1 0 0 . 0} \%)$ \\
Mean \pm SD & $58.49 \pm 11.99$ & $55.21 \pm 13.50$ & $57.71 \pm 12.36$ & $0.31^{* *}$ \\
\hline **= p value was calculated from unpaired student's t-test; *= \\
P value was calculated by Chi-square test corrected by \\
Fisher's Exact test
\end{tabular}

The mean age of total Parkinson's disease patients was $57.71 \pm 12.36$ years ranging from 35 to 82 years with highest percentage $(35 \%)$ had age group 65 years or above, $28.7 \%$ in 55 to 64 years, $22.5 \%$ in 45 to 54 years and lowest percentage (13.8\%) in age group less than 45 years. The mean age of male patients was $58.49 \pm 11.99$ years and of female patients was $55.21 \pm 13.50$ years. It was found that among male patients, highest percentage (37.7\%) had age group 65 years or above, and lowest (11.5\%) in age group less than 45 years; whereas among female patients, highest percentage $(26.3 \%)$ was found in each of the three groups from 45 years and above and $21.1 \%$ in age group less than 45 years. Analysis revealed statistically non-significant age difference between male and female patients in any age group ( $\mathrm{p}>0.05)$ (Table 1$)$.

\section{Presence of Depression}

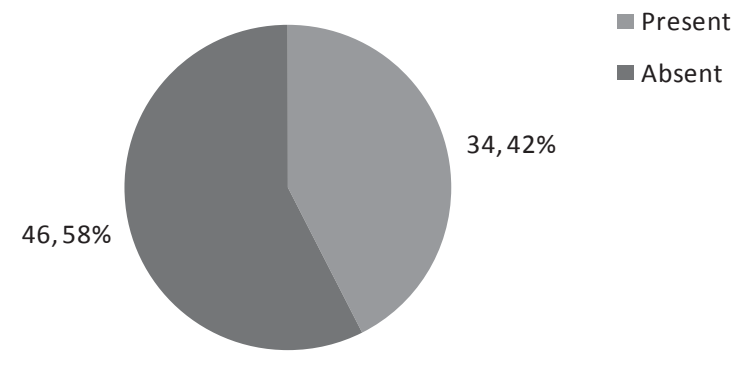

Figure I: Pie diagram showing presence of depression in Parkinson disease patients $(\mathrm{n}=80)$
Among 80 Parkinson's disease patients, depression was present in 34(42\%) patients and was absent in 46(58\%) patients. 95\% confidence interval for population range was between $31.67 \%$ to $53.33 \%$ (Figure I).

Table 2: Presence of Co-morbidities in Study Groups

\begin{tabular}{lccc}
\hline Co-Morbid Illnesses & Group A & Group B & P value \\
\hline Diabetes mellitus & $11.8 \%$ & $23.9 \%$ & \\
Hypertension & $32.4 \%$ & $21.7 \%$ & \\
Other illness & $11.8 \%$ & $15.2 \%$ & $>0.05$ \\
Hypothyroidism & $0.0 \%$ & $2.2 \%$ & \\
\hline
\end{tabular}

*Group A=PD with depression; Group B=PD without depression

Considering co-morbid illnesses, family history and levodopa use it was found that among the depressed patients $11.8 \%$ also suffered from diabetes mellitus (DM), 32.4\% from hypertension (HTN) and 11.8\% from other illness but none from hypothyroidism. Among the non-depressed patients 23.9\% suffered from diabetes mellitus (DM), $21.7 \%$ from hypertension (HTN), 15.2\% from other illness and 2.2\% from hypothyroidism. Family history of PD was present only in $5(6.3 \%)$ patients. Among them 5.9\% had been suffering from depression and $6.5 \%$ not. Levodopa was used by $61.3 \%$ of total PD patients and $38.7 \%$ were drug free. In the depressed group $61.8 \%$ patients used levodopa and 38.2\% were drug free. Analysis revealed that there was no statistically significant difference in terms of co-morbid illnesses, family history and levodopa use between depressed and non-depressed patients $(\mathrm{p}>0.05)$ (Table 2).

Table 3: Factors influencing development of depression in patients of PD

\begin{tabular}{lcccc}
\hline Variables of & Crude Odds ratio P value Adjusted Odds ratio P value \\
\hline Interest & (95\% CI for OR) & \multicolumn{4}{c}{ (95\% CI for OR) } \\
DM & $0.4(0.1-4.6)$ & 0.169 & $0.3(0.8-1.3)$ & 0.125 \\
HTN & $1.7(0.6-4.6)$ & 0.286 & $2.6(0.8-8.2)$ & 0.097 \\
Hypothyroidism & $0.0(0.0-5.2)$ & 1.000 & $0.0(0.0-)$ & 1.000 \\
Other illness & $0.7(0.2-2.6)$ & 0.751 & $0.7(0.1-2.8)$ & 0.595 \\
Family H/O PD & $0.8(0.2-4.7)$ & 1.000 & $0.7(0.1-5.1)$ & 0.758 \\
Levodopa use & $0.9(0.4-2.2)$ & 0.853 & $1.2(0.5-3.2)$ & 0.661 \\
\hline
\end{tabular}

Binary logistic regression analysis

Model Fit: All the 6 variables observed to be associated with development of depressive illness in the patients of Parkinson disease were directly entered into the binary logistic regression model. Hosmer and Lemeshow goodness-of-fit test demonstrated that the model was a perfect fit for the data $(p=0.365)$. After Binary Logistic 
Regression no variable was significantly associated with the development of depressive illness in Parkinson's disease $(\mathrm{p}>0.05)$ (Table 3).

\section{Discussion}

This cross-sectional study was carried out in the department of Neurology and department of Psychiatry, Bangabandhu Sheikh Mujib Medical University from July 2009 to June 2011 for a period of two years. A total of 100 Parkinson's disease patients were interviewed and 80 patients ultimately participated in the study. Data were collected by face to face interview by filling structured clinical questionnaire, then filling up of structured clinical interview for DSM-IV Axis I disorders (SCID-CV) and self-reported 'Depression scale' questionnaire ${ }^{12}$. Patients were divided into two groups considering presence of depression and different variables were compared between two groups. In this study it was found that $42 \%$ of Parkinson's disease patients suffered from depression with $95.0 \%$ confidence interval for population range between $31.67 \%$ to $53.33 \%$. This finding is much above the general population prevalence of Bangladesh (4.6\%). It was found in a WHO supported country wide survey ${ }^{6}$. Moreover this finding is highly similar to previous studies on depression in Parkinson's disease patients. Veiga et $\mathrm{al}^{13}$ found $42 \%$, Cummings ${ }^{14} 40 \%$, Aarsland et $\mathrm{al}^{15} 37 \%$, Starkstein et $\mathrm{al}^{16} 41 \%$, Anguenot et a ${ }^{17} 50 \%$ and Santamaria et $\mathrm{al}^{18}$ found $32 \%$ depression in Parkinson's disease patients. However, Tandberg et $\mathrm{al}^{8}$ reported a rate of $7.7 \%$ of major depression based on DSM-III, revised criteria and $25.1 \%$ based on a score of 17 or higher on the BDI. Therefore, there are variations of frequency due to use of different tools and different cut off scores. Still the rate is quite high in various studies. This finding will probably attract attention of clinicians to search carefully for depression routinely in Parkinson's disease patients.

The mean age of total Parkinson's disease patients was $57.71 \pm 12.36$ years with $58.49 \pm 11.99$ years for male and $55.21 \pm 13.50$ years for female. Highest percentage (37.7\%) had age group 65 years or above. Depression was more common in older age group. This age of study population was consistent with previous study by Salam ${ }^{19}$ who in his study entitled 'Serum testosterone level and its relation with depression in Parkinson disease' and Saha ${ }^{20}$ who in his study entitled 'Natural history of Parkinson disease' found that the mean age of study population was $59.09 \pm 9.45$ years for cases and $58.37 \pm 10.49$ years for control; and $52.6 \pm 14$ years respectively.
In this study there were several chronic incurable co-morbid illnesses like hypothyroidism, DM, hypertension which also may be associated with depression. Among the depressed patients $11.8 \%$ also suffered from diabetes mellitus (DM), 32.4\% from hypertension (HTN) and $11.8 \%$ from other illness but none from hypothyroidism. Gold et $\mathrm{al}^{21}$ in a study on 250 depressed patients showed that $20(8 \%)$ patients had some degree of hypothyroidism including subclinical hypothyroidism. Verma et $\mathrm{al}^{22}$ in a study among five hundred and thirty-seven patients of DM found that the prevalence of depressive symptoms was $31.1 \%$. There is also growing evidence supporting a relationship of depression to higher blood pressure (BP) levels and hypertension (HTN), which are important precursors to heart and vessel damage ${ }^{23}$. However in this study none of the co-morbid illnesses was significantly associated with the development of depressive illness in PD $(p>0.05)$. So these illnesses did not influence the frequency of depression in this study.

Regarding family history of PD, $6.3 \%$ patients had family history of PD; $5.9 \%$ of patients had been suffering from depression and 6.5\% had no depression. No statistically significant difference in terms of family history between depressed and non-depressed patients ( $>0.05$ ) was found. Though positive family history of $\mathrm{PD}$ is considered as a risk factor for depression ${ }^{24}$ small sample size might be a factor in this study. However, Pankratz et $\mathrm{a}^{25}$ in a study on 840 familial PD found no association of depressive symptoms with any genetic variant of PD.

Regarding use of levodopa therapy in study patients, which itself may cause depression; it was found that there was no statistically significant difference between depressed and non-depressed patients in terms of its use $(\mathrm{P}>0.05)$. This is consistent with Menza et $\mathrm{al}^{26}$ who showed that depression and anxiety disorders in PD do not appear to be due to side effects of levodopa therapy. After Binary Logistic Regression none of the co-morbid illnesses, family history of PD and use of levodopa therapy was significantly associated with the development of depressive illness in Parkinson's disease $(p>0.05)$.

\section{Conclusion}

Depression is quite common in Parkinson's disease patients. It is common in older age group. Diabetes mellitus (DM), hypertension (HTN), hypothyroidism, other illness, family history of PD and levodopa use do not significantly influence in the development of 
depressive illness among the Parkinson's disease. Further large scale multi-center study should be carried out to see the real scenario regarding the development of depressive illness among the PD patients.

\section{References}

1. Ropper, AH, Samuels, MA. Degenerative diseases of the nervous system. Adams and Victor's Principles of Neurology, 9th ed, McGraw-Hill, 2009;1033-1051

2. Jankovic J, Shannon KM. Movement Disorders. In: Bradley WG, Daroff RB, Fenichel GM, Jankovic J. Neurology in Clinical Practice, 5th ed, Butterworth Heinemann Elsevier: Philadelphia, 2008;2081-2098

3. De Rijk MD, Tzourio C, Breteler MM, Dartigues JF, Amaducci L, Lopez-Pousa S, Manubens-Bertran JM, Alperovitch A, Rocca WD. Prevalence of parkinsonism and Parkinson's disease in Europe: the EUROPARKINSON Collaborative Study. European Community Concerted Action on the Epidemiology of Parkinson's disease. Journal of Neurology, Neurosurgery Psychiatry. 1997;62(1):10-5

4. Gelder M, Harrison P, Cowen P. Mood disorders. Shorter Oxford Textbook of Psychiatry, 5th ed, Oxford University Press, 2008;217-265.

5. American Psychiatric Association. Diagnostic and Statistical Manual of Mental Disorders, 4th ed, text revision, (DSM-IV-TR), Washington DC: American Psychiatric Association, 2000;345-402.

6. Firoz AH, Karim ME, Alam MF, Rahman AH, Zaman MM. Prevalence, medical care, awareness and attitude towards mental illness in Bangladesh. Bangladesh J Psychiatry. 2006;20(1):9-32.

7. Veazey C, Ozlem Erden Aki S, Cook KF, Lai EC, Kunik ME. Prevalence and treatment of depression in Parkinson's disease. The Journal of Neuropsychiatry and Clinical Neurosciences. 2005;17(3):310-23

8. Tandberg E, Larsen JP, Aarsland D, Laake K, Cummings JL. Risk factors for depression in Parkinson disease. Archives of Neurology. 1997;54(5):625-30.

9. Graeff FG, Guimarães FS, De Andrade TG, Deakin JF. Role of 5-HT in stress, anxiety, and depression. Pharmacology Biochemistry and Behavior. 1996;54(1):129-41.

10. Mayberg HS, Solomon DH. Depression in Parkinson's disease: A biochemical and organic viewpoint' in WJ Weiner and AE Lang, (eds), Behav. Neurol. Movement Disorders. Advances in Neurology 65. Raven Press, New York, 1995;49- 60.

11. DeLong MR, Juncos JL. Parkinson's disease and other movement disorders. In: Fauci AS, Kasper DL, Braunwald E, Hauser SL, Longo DL, Jameson JL, et al., (eds), Harrison's Principles of Internal Medicine, 17th ed, McGraw Hill: New York, 2010;2549-2559.
12. Uddin M, Rahman MM. Development of a scale of depression for use in Bangladesh. Bangladesh psychological Studies. 2005; $15: 25-44$

13. Veiga BA, Borges V, Silva SM, Goulart FD, Cendoroglo MS, Ferraz HB. Depression in Parkinson's disease: clinical-epidemiological correlates and comparison with a controlled group of non-parkinsonian geriatric patients. Brazilian Journal of Psychiatry. 2009;31(1):39-42.

14. Cummings JL. Depression and Parkinson's disease: a review. The American journal of psychiatry. 1992;149(4):443-454

15. Aarsland D, Brønnick K, Alves G, Tysnes OB, Pedersen KF, Ehrt U, Larsen JP. The spectrum of neuropsychiatric symptoms in patients with early untreated Parkinson's disease. Journal of Neurology, Neurosurgery \& Psychiatry. 2009;80(8):928-30.

16. Starkstein SE, Preziosi TJ, Bolduc PL, Robinson RG. Depression in Parkinson's disease. Journal of Nervous and Mental Disease. 1990;178:27-31

17. Anguenot A, Loll PY, Neau JP, Ingrand P, Gil R. Depression and Parkinson's disease: study of a series of 135 Parkinson's patients. The Canadian journal of neurological sciences. Le journal canadien des sciences neurologiques. 2002;29(2):139-46.

18. Santamaria J, Tolosa E, Valles A. Parkinson's disease with depression: a possible subgroup of idiopathic parkinsonism. Neurology. 1986;36(8):1130-1133

19. Salam A. Serum testosterone level and its relation with depression in Parkinson's disease. MD Neurology Thesis, BSMMU, Dhaka, 2010

20. Saha UK. Natural history of Parkinson's disease. [MD Neurology thesis], BSMMU, Dhaka, 2004

21. Gold MS, Pottash AL, Extein IR. Hypothyroidism and depression: evidence from complete thyroid function evaluation. Jama. 1981;245(19):1919-22.

22. Verma SK, Luo N, Subramaniam M, Sum CF, Stahl D, Liow $\mathrm{PH}$, Chong SA. Impact of depression on health related quality of life in patients with diabetes. Ann Acad Med Singapore 2017;39(12):913-917

23. Grewen KM, Girdler SS, Hinderliter A, Light KC. Depressive symptoms are related to higher ambulatory blood pressure in people with a family history of hypertension. Psychosomatic medicine. 2004;66(1):9-16.

24. Cummings JL, Masterman DL. Depression in patients with Parkinson's disease. International journal of geriatric psychiatry. 1999;14(9):711-8

25. Pankratz N, Marder KS, Halter CA, Rudolph A, Shults CW, Nichols WC, Foroud T. Clinical correlates of depressive symptoms in familial Parkinson's disease. Movement disorders: official journal of the Movement Disorder Society. 2008;23(15):2216-23. 26. Menza MA, Robertson-Hoffman DE, Bonapace AS Parkinson's disease and anxiety: comorbidity with depression. Biological psychiatry. 1993;34(7):465-70 